\section{P384 ASSOCIATION OF CHLAMYDIA TRACHOMATIS BACTERIAL LOAD WITH THE PRESENCE OF SYMPTOMS IN STI PATIENTS}

${ }^{1}$ I Brankovic*, ${ }^{2}$ I Malogajski, ${ }^{3} \mathrm{~A}$ Catsburg, ${ }^{4,5} \mathrm{H}$ de Vries, ${ }^{6} \mathrm{~S}$ Ouburg, ${ }^{1,6}$ S Morré. ${ }^{1}$ Institute For Public Health Genomics, Maastricht University, Maastricht, The Netherlands; ${ }^{2}$ School of Health Professions, LIU University Brooklyn, New York City, USA; ${ }^{3}$ Dept. Medical Microbiology and Infection Control, Amsterdam UMC, Amsterdam, The Netherlands; ${ }^{4}$ Dept. of Dermatology, Amsterdam Infection and Immunity Institute, Amsterdam UMC, Amsterdam, The Netherlands; ${ }^{5}$ Dept. of Infectious Diseases, Public Health Service of Amsterdam, Amsterdam, The Netherlands; ${ }^{6}$ Laboratory of Immunogenetics, Dept. Medical Microbiology and Infection Control, Amsterdam UMC, Amsterdam, The Netherlands

\subsection{6/sextrans-2021-sti.419}

Urogenital infection with Chlamydia trachomatis is the most frequently diagnosed sexually transmitted infection (STI) worldwide. The term bacterial load refers to the measurable quantity of bacteria, typically in a clinical sample. This quantity has been associated with transmission ability and the clinical course of a number of infections. In this study, we set out to determine whether the presence of urogenital symptoms of C.trachomatis infection in women correlates with their quantified bacterial load.

Data from a cohort of 226 women patients (Public Health Service of Amsterdam, Infectious Diseases Department, STI outpatient clinic, Amsterdam, The Netherlands) who tested positive for urogenital C.trachomatis infection were used in this study. Patients were also tested for other concurrent STIs to exclude symptoms based on other common urogenital infections. In performing quantification of the Chlamydial load using quantitative PCR approach, the following primers were used: single-copy OmpA gene (MOMP), coding for the major outer membrane protein, and primers targeting the MHC class II antigen (HLA-DQA1) single-copy gene for eukaryotic cell determination. Quantification of HLA gene allowed for normalization of the sample (CT/cell determination). All values for MOMP and plasmid were normalized by means of endogenous control gene HLA. Exclusion criteria were unsuccessful amplification or presence of symptoms in samples with less than $0.01 \mathrm{MOMP} / 100$ cells or and/or plasmids/100 cells that were simultaneously positive for other microorganisms. The latter criterium was introduced in order to ensure that the observed symptoms are not triggered by another urogenital pathogen.

The cohort comprises C. trachomatis serogroups B (51\%), C (14\%) and intermediate (27\%). The remaining patient cases were mixed $(8 \%)$. Currently we are in the process of finalizing the remaining analyses. Preliminary results show there is a relation with CT load and symptoms, as a function of the $\mathrm{Cp}$ PCR value, the HLA load and the performed correction.

\section{P385 RISK, CULTURE, AND NEEDS CORRELATED TO HIV PROGRAM FOR YOUTH IN KOTA KUPANG, EAST NUSA TENGGARA (A QUALITATIVE STUDY)}

L Pasaribu*. National Institute of Health Research and Development, Jl. Percetakan Negara No.29, Jakarta 10560, Indonesia

\subsection{6/sextrans-2021-sti.420}

Background Young people of age 20-49 years were the biggest proportion (70's\%) of cumulative Indonesian People Living With HIV AIDS (PLWHA). Kupang City as capital of East Nusa Tenggara is the entrance for development and has consequences to HIV and STIs. We conducted qualitative research about HIV and ART for pregnant women. The risk, culture, and needs related to the youth arise as concern; therefore we accomplished separated data analysis. This paper aim is to describe the risk, culture, and needs correlated to HIV program for the youth in Kupang City, East Nusa Tenggara.

Method A qualitative research was accomplished in 2017 through in-depth interview and Focus Group Discussion with 55 informants. Discussions were about conditions, risk, culture, and needs that related to HIV programs. Themes that come up then combined to be concluded.

Results Youth in Kupang City have early sexual debut because lack of knowledge about reproductive health, which is considered taboo, while inhabit public lodgings as urbanite due to lack of schools in villages. Sex was trade for lifestyle and economic influences, while shaman provide access for abortion. Traditional marriage is very strongly held, while civil marriage delayed until the dowry fulfilled. Women position is lower and men higher position must be restrained. Increasing tourism area also increases the risks. Needs expressed were character reinforcement began on parents by alarming the community into being careful in preventing HIV transmission, fighting stigma by giving social positions to PLWHA, and intensive health promotion must be given at school.

Conclusion The risks of youth in Kupang City to HIV and STIs arise from lack of knowledge, separation from parents, delayed civil marriage, increasing tourism, and influence of lifestyle and economic needs. Approaches to improve HIV program for the youth need to respect the culture and tackle multidimensional problems.

\section{P386 ACCEPTABILITY OF SELF-COLLECTED SAMPLES FOR DIAGNOSIS OF SEXUALLY TRANSMITTED INFECTIONS AMONG TRANSGENDER WOMEN IN SÃO PAULO COHORT STUDY}

${ }^{1} \mathrm{D}$ McCartney*, ${ }^{2} \mathrm{~T}$ Pinheiro, ${ }^{2} \mathrm{~J}$ Gomez, ${ }^{2} \mathrm{P}$ Galdino, ${ }^{2} \mathrm{M}$ de Sousa Mascena Veras, ${ }^{1} \mathrm{P}$ Mayaud. 'London School of Hygiene and Tropical Medicine, London, UK; ${ }^{2}$ Santa Casa de São Paulo School of Medical Sciences, São Paulo, Brazil

\subsection{6/sextrans-2021-sti.421}

Background As a component of an ongoing cohort study measuring the incidence of HIV among transgender women in São Paulo, Brazil, this study assessed the acceptability of introducing self-collected sampling for the etiological diagnosis of sexually transmitted infections (STIs). Etiological diagnosis would require sampling potential anatomical infection sites, including oropharyngeal, anorectal, urethral, neovaginal and urine samples.

Methods A convenience sample of 23 participants during a scheduled study visit were recruited to this study between October and November 2018. All participants reported being assigned male sex at birth and identified with a feminine gender identity at time of study, with one participant having gender-affirmative surgery to remove their male genitalia. Data collection was through a short investigator-led questionnaire in Portuguese, and included presentation of investigator-designed, gender-neutral instructional diagrams for self-sampling. Three supplemental focus group discussions guided by semi-structured script were conducted in Portuguese between September and October 2019. 
Results All participants $(100 \% ; n=23)$ indicated willingness to provide samples for STI screening during a future study visit. Participant preference was for self-collection of urine samples $(82.6 \% ; \mathrm{n}=19)$, urethral swabs $(81.8 \% ; \mathrm{n}=18)$, and anorectal swabs $(77.3 \% ; \mathrm{n}=17)$. A lower preference for self-collection of oropharyngeal swabs $(47.8 \% ; n=11)$ was observed. Most respondents $(78.3 \% ; \mathrm{n}=18)$ indicated that they would not prefer sampling to be collected by a health professional, mainly due to 'more privacy' $(72.2 \% ; n=13)$. All participants $(n=20 ; 3$ missing) indicated that they would feel comfortable to provide a self-collected sample based on instructional diagrams shown.

Conclusion This study suggested acceptability among transgender women of introducing self-collected sampling for etiological diagnosis of STIs from potential infection sites. Novel gender-neutral instructional diagrams received positive responses of understanding to enable self-collected samples, with further development and testing warranted. Uptake and usability will be explored in TransOdara, a cross-sectional STI prevalence study of transgender women in Brazil.

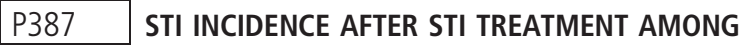 WOMEN AT RISK FOR HIV EXPOSURE INITIATING SAFER CONCEPTION CARE IN SOUTHWESTERN UGANDA}

${ }^{1} \mathrm{P}$ Chitneni ${ }^{*},{ }^{2} \mathrm{M}$ Bwana, ${ }^{3} \mathrm{M}$ Owembabazi, ${ }^{3} \mathrm{~K}$ O'Neil, ${ }^{2} \mathrm{P}$ Kalyebara, ${ }^{2} \mathrm{~W}$ Muyindike, ${ }^{2} \mathrm{~A}$ Byamukama, ${ }^{2} \mathrm{Y}$ Mbalibulha, ${ }^{4} \mathrm{~K}$ Wirth, ${ }^{5} \mathrm{D}$ Bangsberg, ${ }^{6} \mathrm{~J}$ Marrazzo, ${ }^{7} \mathrm{~J}$ Haberer, ${ }^{8} \mathrm{~A}$ Kaida, ${ }^{6} \mathrm{~L}$ Matthews. 'Brigham and Women's Hospital, Boston, USA; ${ }^{2}$ Mbarara Regional Referral Hospital and Mbarara University of Science and Technology, Mbarara, Uganda; ${ }^{3}$ Global Health Collaborative, Mbarara, Uganda; ${ }^{4}$ Botswana Harvard AIDS Institute Partnership, Gaborone, Botswana; ${ }^{5}$ Oregon Health Sciences University and Portland State University School of Public Health, Portland, USA; ${ }^{6}$ University of Alabama at Birmingham, Birmingham, USA; ${ }^{7}$ Massachusetts General Hospital, Boston, USA; ${ }^{8}$ Simon Fraser University, Burnaby, Canada

\subsection{6/sextrans-2021-sti.422}

Background Sexually transmitted infection (STI) recurrence contributes to the high global STI burden. We introduced STI screening and facilitated partner notification $(\mathrm{PN})$ and treatment among women participating in a safer conception study in southwestern Uganda to understand impacts on STI incidence.

Methods A parent study enrolled women planning for pregnancy with a man with HIV or of unknown serostatus to assess pre-exposure prophylaxis use for safer conception. STI screening began after study-start, and all eligible women completed screening for chlamydia, gonorrhea, and trichomoniasis via GeneXpert nucleic acid amplification testing and syphilis via immunochromatographic testing and rapid plasma reagin. Multivariable Poisson regression was used to determine incident STI correlates.

Results Of 134 women in the parent study, 94 underwent enrollment STI screening, of whom 23 were positive. Median age was 31 (IQR 28-35) years. All participants with STIs received counseling and treatment; 21/23 participants accepted PN cards and 18/23 accepted patient-delivered partner medications. By the six-month study-visit, 81 participants repeated STI testing ( $\mathrm{N}=66$ at that visit, $\mathrm{N}=15$ at incident pregnancy visit; whichever came first); 13 participants were lost to follow-up. Of those with enrollment STIs, 19/23 returned for follow-up at six months; 18 reported delivering PN cards and discussing STIs with partner(s) and 14 reported medication delivery to partner(s). Incident STIs occurred in $17 / 81$ participants with 42.57 person-years of follow-up (incidence rate $40 / 100$ person-years). STI incidence was associated with enrollment STI (incidence rate ratio [IRR] 3.39, 95\% confidence interval [CI] 1.22-9.43) and alcohol consumption (IRR 3.18, 95\% CI 1.15-8.85).

Conclusions We demonstrate a high STI prevalence and incidence among women planning for pregnancy in Uganda despite partner treatment promotion efforts. These infections are likely driven in part by re-infection from untreated partners. Novel STI PN interventions are needed to decrease the STI burden, especially among women planning for and with pregnancy.

\section{P388 MYCOPLASMA GENITALIUM-REACTIVE ANTIBODIES IN SERUM AND URETHRAL SPECIMENS OF PERSISTENTLY INFECTED MEN}

${ }^{1} \mathrm{C}$ Kim*, ${ }^{2,3} \mathrm{~L}$ Manheart, ${ }^{2} \mathrm{C}$ Gillespie, ${ }^{2} \mathrm{C}$ Khosropour, ${ }^{4} \mathrm{M}$ Lowens, ${ }^{5,6} \mathrm{P}$ Totten, ${ }^{1} \mathrm{G}$ Wood. ${ }^{\prime}$ Department of Medicine, Division of Allergy and Infectious Diseases, University of Washington, Seattle, USA; ${ }^{2}$ Department of Epidemiology, University of Washington, Seattle, USA; ${ }^{3}$ Department of Global Health, University of Washington, Seattle, USA; ${ }^{4}$ Public Health -Seattle and King County, Seattle, USA; ${ }^{5}$ Department of Medicine, Division of Allergy and Infectious Diseases, University of Washington, Seattle, USA; ${ }^{6}$ Department of Global Health, Pathobiology Interdisciplinary Program, University of Washington, Seattle, USA

\subsection{6/sextrans-2021-sti.423}

Background Mycoplasma genitalium (MG) is a sexually transmitted pathogen associated with acute and chronic genital tract infection in men and women. Although MG-reactive antibodies have been detected in cervicovaginal specimens of infected women, antibodies at the site of infection in men have not been characterized. We compared MG-reactive antibodies in serum and urethral swabs of MG positive and negative men with urethritis to better understand the immunopathogenesis of MG.

Methods Paired urethral swab and serum specimens were collected from men enrolled in a double-blinded study comparing azithromycin and doxycycline for treatment of non-gonococcal urethritis conducted from 2007-2011. Among 22 MG-positive men, antibody reactivity to MG was determined by immunoblot for specimens collected at enrollment and the last MGpositive visit (15-86 days later). Paired specimens from 13 MG-negative men served as controls.

Results In serum specimens, MG-reactive antibodies were detected in all 22 MG-positive men. In 10 men, increasing reactivity to the $\mathrm{MgpB}$ and $\mathrm{MgpC}$ immunodominant adherence proteins occurred over time. In comparison, sera from MG-negative men reacted poorly (7/13) or not at all (6/13) to these proteins. In urethral specimens, MG-specific antibody was detected in 22/22 MG-positive men demonstrating these antibodies are present at the site of infection. Surprisingly, antibody reactivity in urethral specimens decreased over time in $12 / 19$ patients despite the persistence of antibodies in serum and $\mathrm{MG}$ in the urethra. Among MG-negative men, 8/ 13 had detectable $\mathrm{MgpB} / \mathrm{MgpC}$ reactive antibody in urethral specimens but reactivity was very low.

Conclusion Serum antibodies to MG correlated well with infection status, but local antibodies did not. Despite the persistence of $\mathrm{MG}$ in the urethra, antibody reactivity at the site of infection diminished over time. Whether this reduced reactivity reflects reduced bacterial load over time, or whether diminution of local antibodies contributes to persistent infection should be examined in future studies. 